J. Amer. Soc. Hort. Sci. 115(2):329-336. 1990.

\title{
Rapid Generation Cycling of Chrysanthemum Using Laboratory Seed Development and Embryo Rescue Techniques
}

\author{
Neil O. Anderson', Peter D. Ascher ${ }^{2}$, Richard E. Widmer², and James J. Luby \\ Department of Horticultural Science and Landscape Architecture, University of Minnesota, \\ St. Paul, MN 55108 \\ Additional index words. Dendranthema grandiflora, garden chrysanthemums, greenhouse chrysanthemums, embryo \\ rescue, laboratory seed development, self-incompatibility, seed set, germination
}

\begin{abstract}
The generation time ( 0.75 to 1.5 years) in perennial, hexaploid chrysanthemums [Dendranthema grandiflora Tzvelv. (Chrysanthemum morifolium Ramat.)] impedes the rate of progress for sexual breeding programs in creating new clonal cultivars, inbred lines for hybrid seed production, and genetic studies. Modifications to the crossing environment and embryo rescue were evaluated to minimize the chrysanthemum generation cycle. One greenhouse chrysanthemum clone was outcross-pollinated using a bulk pollen source. Following emasculation, inflorescences were either left in situ or the peduncle bases were placed in styrofoam boards floating on a solution of $1 \%$ sucrose and 200 ppm 8-HQC under laboratory conditions. Embryogenesis occurred at a faster rate under laboratory conditions as tested with histological techniques; the heart stage appeared as early as the second day after pollination, compared with 11 days using in situ methods. Total embryogenic development time ranged from 25 (laboratory seed development) to 52+ days (in situ ripening). In a second test, embryo rescue (ER) significantly improved percent seed set, percent germination, and percent of progeny reaching anthesis relative to normal development. ER progeny from both garden parents were significantly earlier in total generation time than corresponding non-ER siblings. Laboratory seed development and ER were then used sequentially to obtain an average progeny generation time of $=100$ days, thus allowing for three generations per year. The potential impact of these two techniques on breeding chrysanthemums and other perennial crops with long generation times is discussed.
\end{abstract}

Improved cultivated garden and greenhouse chrysanthemums (Anderson, 1987; Kitamura, 1976) are the products of public and private sector breeding programs over the past $2000+$ years (Smith and Laurie, 1928). They enjoy popularity on the international market, with some $6000+$ cultivars available (Heywood and Humphries, 1977). Few other floricultural crops have such a diversified and adaptable germplasm base. This versatility can be attributed to an interspecific-hybrid origin involving at least 10 different species (Ackerson, 1967) and aneuploidy ( $2 \mathrm{n}=6 \mathrm{x}=54 \pm 7$ or more chromosomes), the latter causing a high rate of somatic mutations, many of which can be maintained by asexual propagation (Dowrick, 1958; Dowrick and E1-Bayoumi, 1966; Scott, 1957).

Chrysanthemum hybridizing protocols have been improved as optimal conditions for light, temperature, nutrition, and pest control were determined (Cumming, 1945; Ling et al., 1966;

Received for publication 10 Nov. 1988. Univ. of Minnesota Agricultural Experiment Station Scientific Publication Series Paper no. 16,334. The cost of publishing this paper was defrayed in part by the payment of page charges. Under postal regulations, this paper therefore must be hereby marked advertisement solely to indicate this fact.

'Graduate Research Assistant.

${ }^{2}$ Professor.
Oosting and de Jong, 1981; Scott, 1957; Searle and Machin, 1968; Smith and Laurie, 1928). In vitro mutagenesis (Broerjtes et al., 1976; Preil et al., 1983) has proved useful for, and bioreactor somatic embryoid production (Preil et al., 1988) technologies may also be amendable to, asexual propagation and/or breeding. These technological innovations bypass sexual cycles of germplasm improvement involving genetic recombination.

Despite the release of earlier-flowering cultivars, the generation time in perennial chrysanthemums ( 0.75 to 1.5 years; unpublished observations), poses difficulties for sexual breeding programs with objectives as diverse as innovative and competitive clonal cultivars, homozygous inbred lines for hybrid seed production, or germplasm for genetic studies. Perennial outcrossing species possess characteristics that impede germplasm improvement: yearly threshold seed levels, small seed set and brood sizes, complex source-sink interaction, self- and crossincompatibility, inbreeding depression or genetic load, sterilities caused by long-term asexual propagation, lengthy seed development or juvenility periods (Franklin, 1972; Klekowski, 1988, 1988a; Lloyd et al., 1980; Schemske and Lande, 1985; Sorenson, 1969; Stephenson, 1981; Thomson, 1985; Wiens, 1984). Examination of the chrysanthemum life cycle revealed segments that could be shortened by use of appropriate technologies. These 
included reducing the duration of embryogenesis or seed development with embryo rescue (ER) and modifications to the crossing environment.

One modification to the crossing protocols that could decrease the generation time and maximize seed set is water culture or laboratory seed development. This technique was discovered accidentally by Viehmeyer (Scott, 1957) in 1951. Viehmeyer discovered that cut chrysanthemum flowers placed in waterfilled containers set "abundant seed". By 1957, most of the hybrid seed generated at the North Platte, Neb. breeding program originated using this method. The containers did not need to be placed under light for seed development, and it was presumed that the duration of seed development was the same as with in situ methods. This technique offered several advantages over conventional methods, notably the efficiency and convenience of applying pollen from the same male parent to different female parents and decreasing the need for expensive greenhouse space. Subsequent researchers refined the laboratory seed development solution to include charcoal as a "preservative" (Cumming, 1964). To the best of our knowledge, water culture or any modifications thereof, are not currently used by any chrysanthemum breeding program.

In Petunia, nutritive sources were added to the solution, successfully producing seed for breeding programs (Flaschenriem, 1974). Similar nutritive solutions have also been used for woody perennials such as Ulmus (Lester, 1971). Preservative solutions with carbon sources combined with fungicides and bactericide are also currently used for postharvest handling of cut chrysanthemum flowers (Wilkins, 1979). Modifying Viehmeyer's water culture solution to include carbon sources could potentially increase the rate of embryogenesis and maximize seed set. The crossing material would not have to be maintained at standard temperatures (16.7C nights) with diurnal fluctuations as the need for maintaining specific patterns of photosynthesis and respiration would be diminished. Since the pollinated inflorescences would not require photosynthesis with the presence of an alternate carbon source (sucrose), respiration rates at elevated temperatures should not interfere with seed set.

The technique of embryo rescue (ER) has been used successfully in many crops to reduce the generation time (Sanders and Ziebur, 1963) and circumvent postfertilization barriers to recovering interspecific hybrids (Chandler and Beard, 1978; Davies, 1960; Haghighi and Ascher, 1988; Laibach, 1925; Mok et al., 1978; Stimart and Ascher, 1974; Watanabe, 1977). It also has been a useful means for culturing seeds without welldeveloped endosperm (Myers and Ascher, 1982). Globular and heart (or later) stages can be ER using Norstog (1973) or Murashige and Skoog (1962) media, respectively. The use of Norstog medium requires skill, and contamination is often a problem.

Embryogenic stages have been documented for several chrysanthemum species (Harling, 1951; Nagami, 1961; Niwa and Tsutsumi, 1952; Tateishi, 1929; Tanaka and Watanabe, 1972). Chrysanthemums have monosporic Asterad embryo sac development, with one anatropous ovule per ovary or floret wrapped by one integument and a tenuinucellate nucellus. Two hours after pollination, pollen tubes reach the micropyle; 12 to $13 \mathrm{hr}$ later, fertilization is complete (Niwa and Tsutsumi, 1952). Within 8 to 11 days, embryo development in polyploid species has progressed past the globular stage (Drewlow et al., 1975; Watanabe, 1977). Depending on the parent, the duration of seed development and maturation requires 5 to 12 weeks (Cumming, 1945; Searle and Machin, 1968). Additional time is needed for seed harvest, drying, and counting (1 to 2 weeks), sowing and germination ( 2 to 3 weeks), and growth to the true-leaf stage for transplanting ( 2 to 4 weeks). Thus, the period from pollination to transplantation of seedlings can encompass as much as 21 weeks. Coupled with juvenility (de Jong, 1981), flower initiation and development to anthesis $(8+$ weeks, depending on the short day response group), the total generation time can range from 0.75 to 1.5 years. It is plausible that a significant reduction of this time could be realized if heart-stage embryos could be rescued and cultured in vitro.

The objectives of our research were to evaluate the potential use of rapid generation cycling techniques in minimizing the generation cycle for a chrysanthemum breeding program. Two experiments were conducted using laboratory seed development and ER. Experiment 1 compared laboratory water culture vs. in situ seed development duration. The second experiment concerned the effect of ER vs. normal in situ seed development on the total progeny generation time (anthesis to anthesis).

\section{Materials and Methods}

Plants were grown to flowering in $305-\mathrm{cm}^{3}$ pots in glasshouses at St. Paul, Minn. (lat. $45^{\circ} \mathrm{N}$ ), maintained at $24 \pm 5 \mathrm{C}$ days and $15 \pm 1 \mathrm{C}$ nights. The potting medium consisted of 1 soil : 1 sand : 2 sphagnum peat. Mineral nutritional requirements were monitored using biweekly soil tests. Standard insecticidal and fungicidal practices were followed. To induce flower bud initiation and development, short-day photoperiods were provided by covering with black shade cloth (1600-0800 $\mathrm{HR})$. Inflorescences were emasculated and tagged before anthesis for subsequent experiments.

Water culture vs. in situ seed development duration (Expt. 1). The hypothesis tested was that the seed development time between laboratory and in situ conditions would not differ. 'Bluechip', a greenhouse cultivar (Table 1), was chosen for use in this study, since the rate of embryogenesis up to the heart stage has been previously reported (Drewlow et al., 1975; Watanabe, 1977). Outcross pollinations were performed using a composite male bulk pollen source to minimize matched $S$ alleles that would cause cross incompatibility. Pollen was collected from unrelated garden cultivars and bulked using a vacuum pollen collector. Pollinated inflorescences were either left on the plant for in situ seed development or removed for laboratory seed development. For laboratory seed ripening, the peduncle of each inflorescence was inserted in a styrofoam board floating on a solution of $1 \%$ sucrose and 200 ppm 8-hydroxy quinoline citrate (Flaschenriem, 1974; Wilkins, 1979), located 20 to 30 $\mathrm{cm}$ below cool-white fluorescent lights $\left(150 \mu \mathrm{mol} \cdot \mathrm{s}^{-1} \cdot \mathrm{m}^{-2)}\right.$ with a 16-hr photoperiod (0600-2200 HR) at $29 \pm$ IC temperature under laboratory conditions (Fig. 1). Solutions were changed weekly.

Embryogenesis rates were compared for the two seed development techniques using embryos sampled at day 0 (date of pollination), 1, 2, and at 2-day intervals thereafter until seeds were fully mature. Seed coats were removed before histological studies. Histological techniques followed those documented previously for Asteraceae (Harling, 1951). Embryos were sectioned to $10 \mu \mathrm{M}$ in thickness and stained in safranin/fast green.

Embryo rescue vs. in situ progeny generation time (Expt. 2). This experiment tested the hypothesis that there was no difference between embryo rescue (ER) and normal in situ seed development on seed set potential and total progeny generation time (anthesis to anthesis). Two noninbred garden chrysanthemum cultivars were selfed, and these and two greenhouse cultivars were cross pollinated (Table 1) to generate progenies. 
Table 1. Greenhouse and garden chrysanthemum cultivars used as female parents in crossing studies to generate progenies for rapid generation cycling experiments.

\begin{tabular}{|c|c|c|c|c|}
\hline Cultivar & $\begin{array}{c}\text { Type of } \\
\text { chrysanthemum }\end{array}$ & $\begin{array}{c}\text { Short-day } \\
\text { response } \\
\text { group }^{z} \\
\text { (weeks) }\end{array}$ & $\begin{array}{l}\text { Crosses } \\
\text { performed }\end{array}$ & $\begin{array}{c}\text { Progeny } \\
\text { cross } \\
\text { number }\end{array}$ \\
\hline Bluechip & Greenhouse & 9 & Bulk outcross & 86-N706 \\
\hline $\begin{array}{l}\text { Golden Yellow } \\
\text { Princess Anne }\end{array}$ & Greenhouse & 10 & Bulk outcross & 86-N707 \\
\hline Royal Knight & Garden & $7-8$ & $\begin{array}{c}\text { Selfed } \\
\text { Bulk outcross }\end{array}$ & $\begin{array}{l}86-N 708 \\
86-N 709\end{array}$ \\
\hline Royal Pomp & Garden & $7-8$ & $\begin{array}{c}\text { Selfed } \\
\text { Bulk outcross }\end{array}$ & $\begin{array}{l}86-N 710 \\
86-N 711\end{array}$ \\
\hline
\end{tabular}

${ }^{2}$ Number of weeks of short-days at $17 \mathrm{C}$ required to reach anthesis.
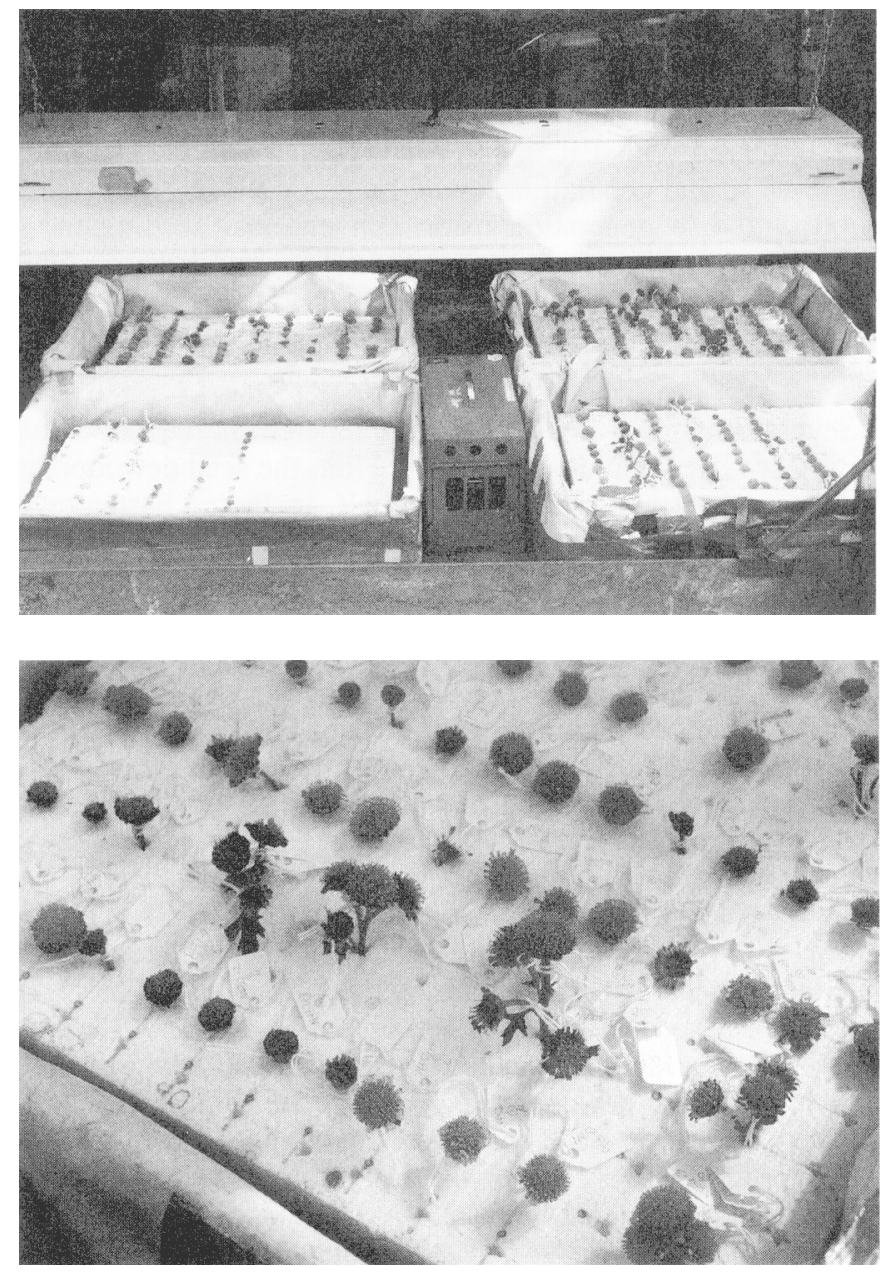

Fig. 1. Laboratory seed development conditions (Top) for Expt. 1. Stem bases of each single or multiple-headed inflorescence were inserted into styrofoam boards (Bottom) floating in a solution of $1 \%$ sucrose and 200 ppm 8-hydroxy quinoline citrate.

Greenhouse cultivars were not selfed, because previous crossing studies (unpublished data) showed that they possess a strong sporophytic self-incompatibility system (Drewlow et al., 1973) and frequently have few hermaphroditic disk florets that are pollen sources. Outcross pollinations were performed on 16 June 1986, using pollen collected and bulked from unrelated garden cultivars.

Figure 2 outlines the treatments that the seed heads received following pollination. The pollination date represented day 0 for the generation time clock, while the dates of anthesis for each progeny were the ending dates used to depict the total generation time (anthesis to anthesis). A split-split plot design with main effects confounded was set up for the embryo rescue treatment. Whole plots were the sampling dates of $8,9,11,19$, and 24 days postpollination, at which time the in florescences were removed from the plants. Day 8 was selected as the first sampling date because earlier dates were at the pre-heart stage (Drewlow et al., 1975) and could not be ER without using Norstog medium. Each seed head was divided in half (as split-plots) following disinfestation in 95\% ethanol (for 1 rein) under a Iaminar flow hood; the embryos were rescued either with or without seed coat removal. Comparisons were made between percent seed set, germination, and progeny reaching anthesis for ER and non-ER treatments using paired $\mathrm{x}^{2}$ tests.

Embryos were placed on Murashige-Skoog (MS) tissue culture medium with $1 \%$ sucrose and without plant growth regulators (Murashige and Skoog, 1962; Stimart and Ascher, 1974) in baby food jars. Cultured embryos subsequently were placed in an unlighted growth chamber at $21 \pm 0.1 \mathrm{C}$ for germination. Upon germination, the culture vessels were placed at room temperature $(29 \pm 1 \mathrm{C})$ with a $16-\mathrm{hr}$ photoperiod $(0600-2200 \mathrm{HR})$

\section{Emasculation and pollirration of inflorescences}

Inflorescences (whole plots) were sampled

$$
8,9,11,19 \text {, and } 24 \text { days }
$$

post-pollination

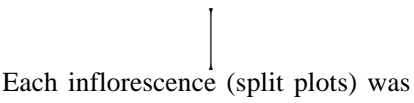

divided in half. Embryos rescued

had the seed coats removed or not removed.

Rescued embryos placed in vitro on Murashige-Skoog medium

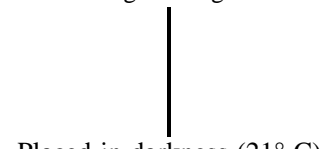

Placed in darkness $\left(21^{\circ} \mathrm{C}\right)$ for germination.
Infloresences remain on plant 6-8 weeks for seed maturation Inflorescences harvested. Seeds were dried, cleaned and counted. $\left.\right|_{\text {Seeds sown on soil and }}$ under standard greenhouse condition

Transferred to light $\left(29^{\circ} \mathrm{C}\right)$ Seedlings grown to true and grown in vitro until true leaf stage. leaf stage after germination.

Seedlings transplanted and transferred to greenhouse conditions $\left(15^{\circ} \mathrm{C}\right)$ with short day photoperiods accomplished with blackout shade cloth.

Date of anthesis (to first flower) recorded for each seedlings within each progeny.

Fig. 2. The scheme of embryo rescue and normal in situ seed development, germination, and flowering of chrysanthemum progenies (Expt. 2). 
supplied by cool-white fluorescent lights $\left(92 \mu \mathrm{mol} \cdot \mathrm{s}^{-1} \cdot \mathrm{m}^{-2}\right)$ until true leaves appeared. At this stage, the seedlings were transferred from in vitro culture to standard glasshouse conditions along with in situ-developed seedlings germinated under standard conditions (Ling et al., 1966; Scott, 1957).

\section{Results}

Experiment 1. Histological studies indicated that embryogenesis occurred at a faster rate in detached inflorescences under laboratory conditions than in in situ in florescences. There were no abortive embryos observed in the laboratory seed development treatment, whereas several were noted among the in situ treatment. At day 0 (date of pollination), histological sections confirmed a previous report (Harling, 1951) of an anatropous ovule with one integument developing from the base of the tenuinucellate, single-layered nucellus (Fig. 3 top left). At this time, the chalazal antipodal fills about one-third of the embryo sac cavity.

Endosperm cells were irregularly shaped and difficult to follow through the various embryogenic stages. A globular embryo with a well-defined hypophysis and suspensor (Fig. 3 top right) was present at day 1 (laboratory seed development treatment). By day 2, the embryo was at the heart stage (Fig. 3 center left), indicating that the embryos could be rescued onto MS medium from this date forward. The torpedo stage occurred at day 4 (Fig. 3 center right) and the embryo was fully mature at day 25 (Fig. 3 bottom right). In situ-developed embryos developed uniformly at a much slower rate (histological sections not shown), reaching maturity $52+$ days postpollination (Fig. 4).

Experiment 2. 'Royal Knight' and 'Royal Pomp' were selfincompatible in this experimental environment and did not set any seed following self-pollination. In addition, 'Golden Yellow Princess Anne' may be female-sterile, since no outcross seed was obtained. Percent seed-set data (Table 2) were calculated for each inflorescence as total seed number/total number of florets pollinated (Anderson et al., 1988). In all crosses where seed set was obtained, the ER and non-ER treatments differed significantly from the expected 1:1 $\mathrm{x}^{2}$ ratios (Table 3); ER crosses were higher for all traits compared with non-ER crosses. The near-optimal conditions provided by the ER treatment improved seed set and germination percentages by as much as $56 \%$ and $46 \%$, respectively. The ER treatment improved the percent progeny reaching anthesis, indicating that normal germination procedures eliminated a significant percentage of the potential flowering progeny.

Non-ER seeds germinated within 1 to 2 weeks after sowing, demonstrating that dormancy does not exist in this species. Embryos rescued at post-heart stages with the seed coat removed germinated often as soon as $24 \mathrm{hr}$ post-ER. Embryos with seed coats intact did not germinate within 4 months post-ER (Table 4), indicating the necessity of seed coat removal to germinate ER seedlings. In addition, contamination was frequent when seed coats were not removed. Contaminated embryos that were disinfested and recultured did not germinate.

To reduce the bias of treatments having zero values resulting from germination failures when seed coats were not removed before ER (Table 4), results from days 8 and 9 and crosses 86N710, 86-N708, and 87-N707 were removed before split-split plot analysis. The remaining data from days 11,19 , and 24 for three crosses, 86-N709, 86-N706, and 86-N711, were used for analysis. Anderson's (1946) formulae were used for inserting estimates of missing values to calculate SES (Cochran and Cox,
1957). In the analysis of variance, $1 \mathrm{df}$ is subtracted from the appropriate error $\mathrm{df}$ for each of the 11 missing observations. Consequently, the error $\mathrm{df}$ remaining was extremely low $(\mathrm{df}=$ 1) and would present a large bias in calculating the error mean square. Thus, analysis was not possible. Statistical significance cannot be attached to the differences seen between date of ER, seed coat removal, and the cross performed, although the biological significance is evident.

Progeny generation times (from anthesis to anthesis) appear in Fig. 5. In some crosses, progeny rosetted and failed to flower. Rosetted progeny were placed in a 6-week cool-temperature treatment (3C) to induce bolting and flowering. However, rosetted plants failed to flower subsequent to the cold treatment and were not included in the histograms in Fig. 5. The latest ER progeny always flowered earlier than the earliest non-ER plants, regardless of the female parent short-day (SD) response group (Table 1).

ER progeny from both garden parents flowered earlier than their corresponding non-ER siblings (Fig. 5). The generation time observed with ER, using early garden parents, indicated that three sexual generations could be produced in 1 year, compared with one generation using conventional seed ripening. This was not the case, however, for 'Bluechip' because of its longer SD response group requirement.

\section{Discussion}

Several important implications are inherent in the use of laboratory seed development (Expt. 1). First, the seed development cycle was shortened by almost one-half, including hastening of the date of heart stage and, thus, the potential date of ER. The earliest date of heart stage ER was more than 9 days earlier than that of in situ-developed embryos (comparing 86-N706 in Expts. 1 and 2). Since the duration of seed development using Viehmeyer's water culture was presumably the same as in situ methods, the addition of carbon sources may have been the causal agent for reduced seed development time in this experiment.

Second, the continuation of embryogenesis under the high, constant temperature (29C) in the laboratory indicated that a wider range of temperatures could be tolerated in the crossing environment, thus allowing for crossing during summer instead of only spring or fall (Searle and Machin, 1968). Subsequent bulk outcross pollinations using hybrid, nonclonal genotypes $(n=48)$ indicated that seed-set levels of $100 \%$ could be obtained (data not shown). Source-sink interactions and/or water stresses that occur with in situ seed development appear to be minimized, if not entirely eliminated. Based on these results, all 1987 hybrid and inbred progeny produced for the Univ. of Minnesota breeding program were generated successfully using this technique.

Third, the increased rate of embryogenesis in the laboratory was not due simply to higher temperatures. Heat units were calculated from thermograph charts for each environment using 16.7C as the base temperature for adequate growth of the species. For each day, the base temperature was subtracted from the high temperature and the differences were summed for each treatment environment. The greenhouse environment (in situdeveloped seed) had 934 degree days, while only 382 were calculated for the laboratory environment. At day 26, the greenhouse environment had degree days equaling that of the laboratory. At this stage, the greenhouse in situ-developed embryos were only at the late heart stage, while the laboratory-ripened embryos were fully mature (Fig. 4). Since degree days did not explain the observed increased rate of embryogenic develop- 

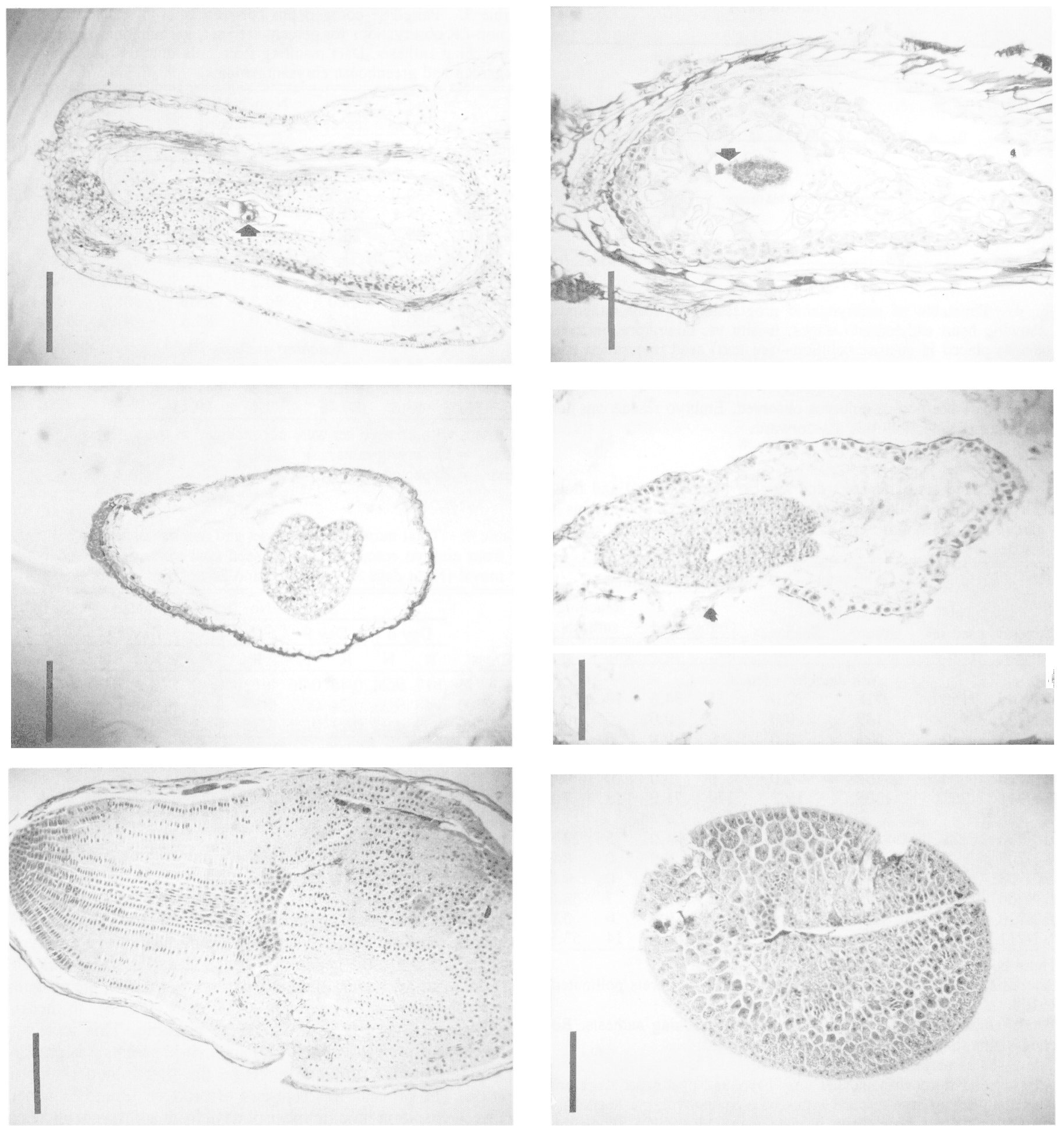

Fig. 3. Stages of embryogenesis occurring in chrysanthemum inflorescences developed under laboratory conditions by placement in a $1 \%$ sucrose and $200 \mathrm{ppm}$ 8-hydroxy quinoline citrate solution at 29C. Embryo sac (top left) with an unfertilized egg cell (arrow) at day O; (top right) globular embryo at day 1 (arrow designates hypophysis); (center left) heart stage at day 2; (center right) torpedo on day 4; (bottom left) cotyledonary at day 6 with the apical dome defined and vascular traces appearing in the cotyledons, and (bottom right) a mature seed occurring at day 25 . Bars $=0.1 \mu \mathrm{m}$.

ment, it was possible that source-sink alterations occurred, causing a greater sink strength in the laboratory-developed embryos than those on the plant.

Fourth, laboratory seed development facilitated a more efficient and convenient physical arrangement for crossing. Selfing or outcross pollination was quicker and easier since all the inflorescences were in close proximity. If one male parent was to be crossed with several females, the female parent inflorescences could be placed in the same row in the styrofoam board and pollen could be rapidly applied. In addition, plants did not 
Time (in days)

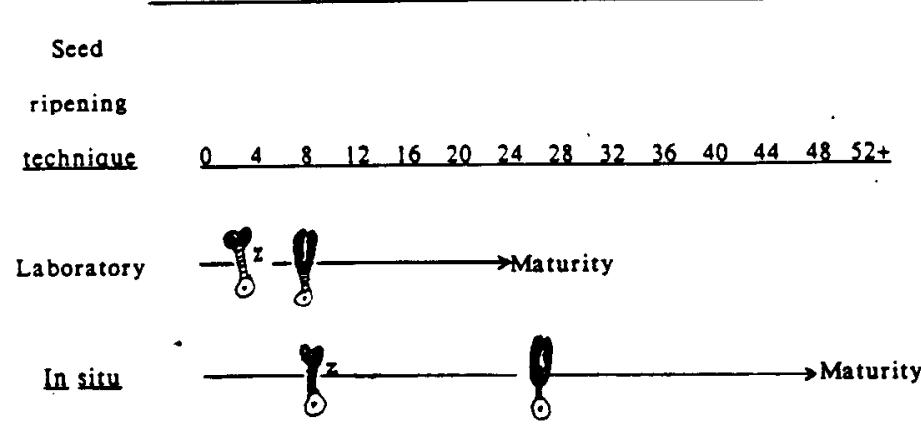

Fig. 4. Timetable of embryogenic progression in chrysanthemum showing heart and torpedo stages; in situ vs. laboratory (inflorescences placed in sucrose solution-see text) seed maturation conditions. Outcross and self-pollinations were performed on 16 June 1986.

${ }^{2}$ Denotes date heart-stage embryos observed. Embryo rescue can proceed at any time from this day forward.

Table 2. Seed set parameters and number of germinated and flowering seedlings resulting from self and bulk outcross pollinations of garden and greenhouse chrysanthemums with and without embryo rescue.

\begin{tabular}{|c|c|c|c|c|c|c|c|}
\hline \multirow{3}{*}{$\begin{array}{c}\text { Cross } \\
\text { number }\end{array}$} & \multirow{3}{*}{$\begin{array}{c}\text { Total } \\
\text { seed set } \\
\text { (No.) }\end{array}$} & \multirow{3}{*}{$\begin{array}{l}\text { Total } \\
\text { pollinated } \\
\text { florets } \\
\text { (No.) }\end{array}$} & \multirow{3}{*}{$\begin{array}{c}\text { Seed sety } \\
(\%)\end{array}$} & \multicolumn{4}{|c|}{ Seedlings } \\
\hline & & & & \multicolumn{2}{|c|}{ Germinated } & \multicolumn{2}{|c|}{$\begin{array}{c}\text { Reaching } \\
\text { anthesis }\end{array}$} \\
\hline & & & & No. & $\%^{\mathrm{w}}$ & No. $x$ & $\%^{\mathrm{w}}$ \\
\hline \multicolumn{8}{|c|}{ Non-embryo rescued } \\
\hline $87-N 706$ & 158 & 718 & 22.0 & 55 & 34.5 & 10 & 6.3 \\
\hline $86-\mathrm{N} 707$ & 0 & 149 & 0.0 & 0 & 0.0 & 0 & 0.0 \\
\hline $86-N 708$ & 0 & 523 & 0.0 & 0 & 0.0 & 0 & 0.0 \\
\hline $86-N 709$ & 59 & 487 & 12.1 & 51 & 85.7 & 17 & 28.8 \\
\hline $86-N 710$ & 0 & 152 & 0.0 & 0 & 0.0 & 0 & 0.0 \\
\hline $86-N 711$ & 252 & 1305 & 19.3 & 179 & 71.0 & 18 & 7.1 \\
\hline \multicolumn{8}{|c|}{ Embryo rescued } \\
\hline $86-N 706$ & 21 & 68 & 30.9 & 17 & 81.0 & 5 & 23.8 \\
\hline $86-N 707$ & 0 & 84 & 0.0 & 0 & 0.0 & 0 & 0.0 \\
\hline $86-N 708$ & 0 & 47 & 0.0 & 0 & 0.0 & 0 & 0.0 \\
\hline $86-N 709$ & 13 & 99 & 68.1 & 12 & 92.3 & 7 & 53.8 \\
\hline $86-N 710$ & 0 & 24 & 0.0 & 0 & 0.0 & 0 & 0.0 \\
\hline $86-N 711$ & 26 & 68 & 38.2 & 26 & 100.0 & 14 & 53.8 \\
\hline
\end{tabular}

${ }^{2}$ There is one ovule per floret.

${ }^{\mathrm{y}}$ Percent seed set $=($ total seed set/total number of florets pollinated $)$ $\times 100$.

Total number of plants within each progeny reaching anthesis. Rosetted plants that did not flower are not included.

"Expressed as percentages of total seed set.

"Seed set and floret data include only heart and post-heart stage embryos that were embryo rescued with seed coat removal; pre-heart stage embryos could not be embryo rescued using Murashige-Skoog medium.

need to be maintained in the greenhouse for the 5 to 12 weeks needed to develop seeds on the plant.

Embryo rescue (ER) significantly shortened the progeny generation time when the female parents were in the 7- to 8-week SD response group (Fig. 5). Even with 9-week female ('Bluechip'), the latest ER progeny reached anthesis earlier than the earliest non-ER progeny, although the average generation time for both groups overlapped. ER was an efficient technique for generating progeny for both greenhouse and garden cultivars,
Table 3. Paired $x^{2}$ comparisons between embryo rescued (ER) and non-ER observations for percent seed set, germination, and progeny reaching anthesis. Data resulting from bulk outcross pollinations of garden and greenhouse chrysanthemums.

\begin{tabular}{|c|c|c|c|c|c|c|}
\hline \multirow{2}{*}{$\begin{array}{c}\text { Cross } \\
\text { number }\end{array}$} & \multicolumn{2}{|c|}{ Embryo rescued } & \multicolumn{2}{|c|}{$\begin{array}{c}\text { Non-embryo } \\
\text { rescued }\end{array}$} & \multirow[b]{2}{*}{$\chi^{2}$} & \multirow[b]{2}{*}{$P$ value } \\
\hline & Obs. ${ }^{y}$ & Exp. ${ }^{x}$ & Obs.y & Exp. ${ }^{x}$ & & \\
\hline \multicolumn{7}{|c|}{ Seed set (\%) } \\
\hline $86-N 706$ & 30.9 & 26.45 & 22.0 & 26.45 & 1.5 & $0.2-0.3$ \\
\hline $86-N 709$ & 68.1 & 40.1 & 12.1 & 40.1 & 39.1 & $<0.01$ \\
\hline $86-N 711$ & 38.2 & 28.75 & 19.3 & 28.75 & 6.2 & $0.01-0.05$ \\
\hline \multicolumn{7}{|c|}{ Germination (\%) } \\
\hline $86-N 706$ & 81.0 & 57.75 & 34.5 & 57.75 & 18.72 & $<0.01$ \\
\hline $86-\mathrm{N} 709$ & 92.3 & 89.0 & 85.7 & 89.0 & 0.25 & $0.5-0.7$ \\
\hline $86-N 711$ & 100.0 & 85.5 & 71.0 & 85.5 & 4.92 & $0.01-0.05$ \\
\hline \multicolumn{7}{|c|}{ Reaching anthesis (\%) } \\
\hline $86-N 706$ & 23.8 & 15.05 & 6.3 & 15.05 & 10.17 & $<0.01$ \\
\hline $86-N 709$ & 53.8 & 41.3 & 28.8 & 41.3 & 7.56 & $<0.01$ \\
\hline $86-N 711$ & 53.8 & 30.45 & 7.1 & 30.45 & 35.8 & $<0.01$ \\
\hline
\end{tabular}

${ }^{2}$ Crosses with no seed set were not included in the analysis.

'Obs. = Observed value.

${ }^{y}$ Exp. = Expected value.

Table 4. Total number of seeds set and number of florets pollinated from embryo rescue (ER) with seed coat removal (R) and nonremoval $(\mathrm{N})$ at days $8,9,11,19$, and 24 postpollination.

\begin{tabular}{|c|c|c|c|c|c|c|c|c|c|c|}
\hline \multirow[b]{3}{*}{ Cross $^{2}$} & \multicolumn{10}{|c|}{ Seed set/No. florets pollinated } \\
\hline & \multicolumn{2}{|c|}{ Day 8} & \multicolumn{2}{|c|}{ Day 9} & \multicolumn{2}{|c|}{ Day 11} & \multicolumn{2}{|c|}{ Day 19} & \multicolumn{2}{|c|}{ Day 24} \\
\hline & $\mathrm{R}$ & $\mathrm{N}$ & $\mathrm{R}$ & $\mathrm{N}$ & $\mathrm{R}$ & $\mathrm{N}$ & $\mathrm{R}$ & $\mathrm{N}$ & $\mathrm{R}$ & $\mathrm{N}$ \\
\hline $86-\mathrm{N} 711$ & $0 / 17$ & $0 / 24$ & $0 / 46$ & $0 / 36$ & $0 / 13$ & $0 / 40$ & $17 / 45^{y}$ & $0 / 29$ & $4 / 24$ & $0 / 40$ \\
\hline $86-N 709$ & $0 / 48$ & $0 / 32$ & $0 / 34$ & $0 / 32$ & $0 / 20$ & $0 / 46$ & $4 / 39 y$ & $0 / 20$ & $9 / 49$ & $0 / 26$ \\
\hline $86-N 706$ & $0 / 53$ & $0 / 32$ & $0 / 21$ & $0 / 25$ & $4 / 35^{y}$ & $0 / 25$ & $13 / 27$ & $0 / 13$ & $2 / 4$ & $0 / 21$ \\
\hline
\end{tabular}

increasing both the percent germination and percent reaching anthesis compared with the non-ER treatments.

The next logical question was whether the use of both techniques simultaneously could ensure maximal seed set potentials, decrease the time required for developing heart stage embryos, and reduce the total generation time. If earlier $(\leq 8$-week SD response group) female and male parents were used, the progeny generation time should average $\approx 100$ days (Fig. 5). In theory, three generations per year should be possible. This idea was tested by self-pollinating 66 inbred and hybrid parents (via pseudoself compatibility, PSC) to generate the first inbred (I1) generation. The process was repeated to produce 12 and 13 generations. Generation time (number of days from anthesis to anthesis) was recorded for each inbred generation. Progeny in each generation were selected for male and female fertility and PSC, but not for any horticultural traits (e.g., flowering earliness) that would bias the results.

The total generation time for the three cycles was $<1$ year, indicating that the two laboratory techniques can be used simultaneously to produce rapid generation cycling (RGC) chrysanthemums. This procedure allows for inbreeding to proceed rapidly, thus achieving homozygosity faster and permitting quicker genetic analysis time than would otherwise be possible. In addition, the use of RGC techniques eliminated the need to spend years of selection to obtain germplasm that is genetically rapid- 

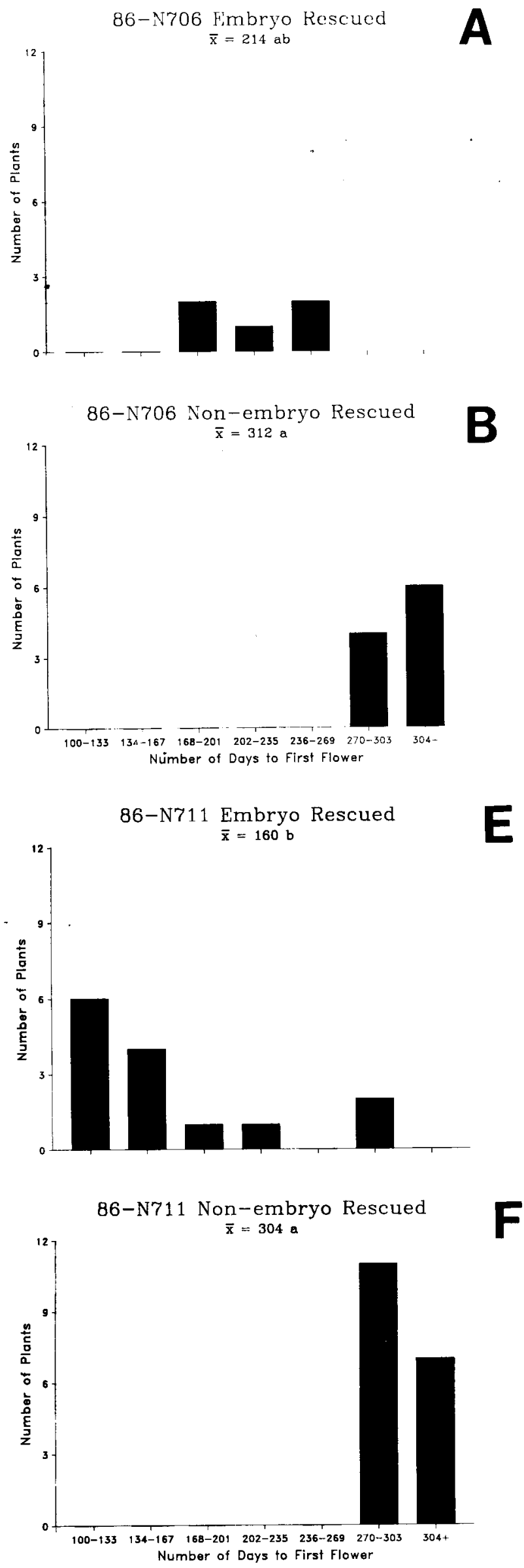
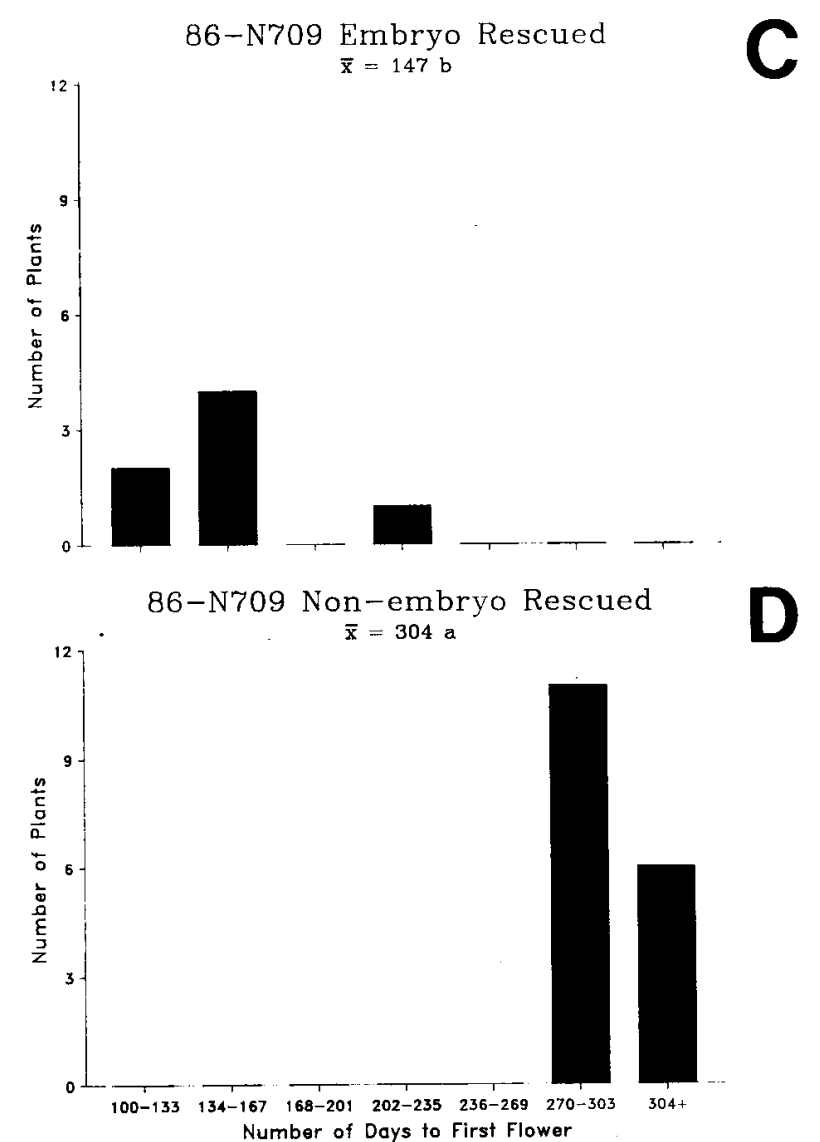

Fig. 5. Histogram of the number of days to first flower for embryo rescued and non-embryo-rescued chrysanthemum progenies. The average number of days $(\mathrm{x})$ per generation cycle for each progeny were analyzed using the LSD test at $P=0.05$ (LSD $=111)$.

cycling, as has been done with Brassica (Williams and Hill, 1986).

The ability to generate three inbred generations per year is unprecedented in a perennial crop such as chrysanthemum, where long generation times are due to juvenility, resetting, and lengthy SD requirements for flower bud initiation and development. In other herbaceous perennials where seed dormancy necessitates a stratification period, rapid generation cycling techniques may be useful in not only shortening the embryogenic cycle, but also in alleviating the requirement for stratification. Use of rapid generation cycling techniques may also hasten the formulation of theoretical models for inbreeding depression or genetic load, heterosis, F1 hybrid development, and self incompatibility genetics in chrysanthemum.

\section{Literature Cited}

Ackerson, C. 1967. Original species of the chrysanthemum. Natl. Chrysanthemum Soc. Bul. 23(3):105-107.

Anderson, N.O. 1987. Reclassification of the genus Chrysanthemum L. HortScience 22(2):313.

Anderson, N. O., B.E. Liedl, P.D. Ascher, R.E. Widmer, and S.L. Desborough. 1988. Evaluating self incompatibility in Chrysanthemum: the influence of ovule number. Sexual Plant Reprod. 1: 173181.

Anderson, R.L. 1946. Missing-plot techniques. Biom. Bul. 2:41-47. Broerjtes, C., S. Roest, and G.S. Bokelmann. 1976. Mutation breeding of Chrysanthemum morifolium Ram. using in vivo and in vitro adventitious bud techniques. Euphytica 25:11-19.

Chandler, J.M. and B.H. Beard. 1978. Sunflower interspecific hy- 
bridization using embryo culture, 8th Intl. Sunflower Conf. 1978. Minneapolis. p. 510-515.

Cochran, W. G., and G.M. Cox. 1957. Experimental designs. 2d ed. Wiley, New York.

Cumming, A. 1945. Hardy chrysanthemums. rev. ed. Doubleday, Garden City, N.Y.

Cumming, R.W. 1964. The chrysanthemum book. D. Van Nostrand, Princeton, N.J.

Davies, D.R. 1960. The embryo culture of interspecific hybrids of Hordeum, New Phytol. 59:9-14.

de Jong, J. 1981. Effects of irradiance and juvenility on the selection of chrysanthemums. Euphytica 30(2):493-500.

Dowrick, G.J. 1958. Chromosome numbers and the origin and nature of sports in the garden chrysanthemum. Natl. Chrysanthemum Sot. Yrbk. p. 60-79.

Dowrick, G.J. and A. E1-Bayoumi. 1966. The origin of new forms of the garden Chrysanthemum. Euphytica 15:32-38.

Drewlow, L. W., P.D. Ascher, and R.E. Widmer. 1973. Genetic studies of self incompatibility in the garden chrysanthemum, Chrysanthemum morifolium Ramat. Theor. Applied Genet. 43(1):1-5.

Drewlow, L. W., P.D. Ascher, and R.E. Widmer. 1975. Rapid method of determining pollen incompatibility in Chrysanthemum morifolium Ramat. Euphytica 24:29-32.

Flaschenriem, D.R. 1974. Anew method of producing Petunia hybrids seed in vitro. MS Thesis, Mankato State College, Mankato, Minn.

Franklin, E.C. 1972. Genetic load in loblolly pine. Amer. Nat. 106:262265.

Haghighi, K.R. and P.D. Ascher. 1988. Fertile, intermediate hybrids between Phaseolus vulgaris and P. acutifolius from congruity backcrossing. Sexual Plant Reprod. 1:51-58.

Harling, G. 1951. Embryological studies in the composite. Part II. Anthemideae-Chrysantheminae. Acts Horta Bergiani 16:2-56.

Heywood, V.H. and C.J. Humphries. 1977. Anthemideae-systematic review, p. 851-898, In: V.H. Heywood, J.B. Harborne, and B.L. Turner (eds.). The biology and chemistry of the Composite. Academic, New York.

Kitamura, S. 1976. Dendranthema et Nipponanthemum. Acts Phytotaxonomica et Geobotanical 29:165-170.

Klekowski, E.J, 1988. Mutation, developmental selection, and plant evolution. Columbia Univ. Press, New York.

Klekowski, E.J. 1988a. Progressive cross- and self-sterility with aging in fern clones and perhaps other plants. Heredity $61: 247-253$.

Laibach, D. 1925. Das Taubwerden von Bastardsamen und die kunstliche Aufzucht früh absterbender Bastard-Embryonen. Zeit. Bot. 17:417-459.

Lester, D.T. 1971. Self-compatibility and inbreeding depression in American elm. For. Sci. 17(3):321-322.

Ling, L., R.E. Widmer, and R. Mullin. 1966. Influence of temperature, nutrition and combining ability on seed production in chrysanthemum. Proc. Amer. Soc. Hort. Sci. 88:621-626.

Lloyd, D. G., C.J. Webb, and R.B. Primack. 1980. Sexual strategies in plants. II. Data on the temporal regulation of maternal investment. New Phytol. 86:81-92.

Mok, D.W.S., M.C. Mok, and A. Rabakoarihanta. 1978. Interspecific hybridization of Phaseolus vulgaris with $P$. lunatas and $P$. acutifolius. Theor. Applied Genet. 52:209-215.

Murashige, T. and F. Skoog. 1962. A revised medium for rapid growth and bio assays with tobacco tissue cultures. Physiol. Plant. 15:473497.
Myers, P .J. and P.D. Ascher. 1982. Culture of North American orchids from seed. HortScience 17(4):550.

Nagami, S. 1961. Genecological and horticultural studies on some species of chrysanthemum in east Japan. Yokohama National Univ. Sci. Rpt. Sect. 2(8):1-28.

Niwa, T. and H. Tsutsumi. 1952. Structure of the ovary and fertilization of the chrysanthemum. Jpn. Inst. Landscape Arch. J. 15:2631.

Norstog, K. 1973. New synthetic medium for the culture of premature barley embryos. In Vitro 5(4):307-308.

Oosting, 1. and J. de Jong. 1981. Veel licht en $14^{\circ} \mathrm{C}$ ideaal voor kruisen chrysant. Vakblad voor de Bloemisterij 36(25):28-31.

Preil, W., M. Engelhardt, and F. Walther. 1983. Breeding of low temperature tolerant poinsettia (Euphorbia pulcherrima) and chrysanthemum by means of mutation induction in in vitro culture. Acts Hort. 131:345-351.

Preil, W., P. Florek, U. Wix, and A. Beck. 1988. Towards mass propagation by use of bioreactors. Acts Hort. 226(1):99-106.

Sanders, M.E. and N.K. Ziebur. 1963. Artificial culture of embryos, p. 297-325. In: P. Maheshwari (cd.). Recent advances in the embryology of angiosperms. Intl. Sot. Plant Morphol. Univ. of Delhi. Delhi, India.

Schemske, D.W. and R. Lande. 1985. The evolution of self-fertilization and inbreeding depression in plants: 11. Empirical observations. Evolution 39(1):41-52.

Scott, E.L. 1957. The breeder's handbook. Dancey Printing Co., Bogota, N.J. Natl. Chrysanthemum Sot. Hdbk 4.

Searle S.A. and B.J. Machin. 1968. Chrysanthemums the year round. Blandford, London.

Smith, E.D. and A. Laurie. 1928. Chrysanthemum breeding. Mich. Agr. Expt. Sta. Spec. Bul. 186.

Sorenson, F. 1969. Embryogenic genetic load in coastal Douglas fir, Pseudotsuga menziesii var. menziesii. Amer. Nat. 103:389-398.

Stephenson, A.G. 1981. Flower and fruit abortion: proximate causes and ultimate functions. Ann. Rev. Ecol. \& Syst. 12:253-279.

Stimart, D. and P.D. Ascher. 1974. Culture medium suitable for growing small excised lily embryos. North Amer. Lily Sot. Yrbk. 37:7784.

Tanaka, R. and K. Watanabe. 1972. Embryological studies in Chrysanthemum makinoi and its hybrid crossed with hexaploid Ch. japonense. J. Sci. Hiroshima Univ. Series B, Div. 2 (Botany) 14(2):7584.

Tateishi, S. 1929. Embryologische Studien an der Gattung Chrysanthemum. Jpn. J. Bet. 4:317-327.

Thomson, J.D. 1985. Pollination and seed set in Diervilla lonicera (Caprifoliaceae): temporal patterns of flower and ovule deployment. Amer. J. Bet. 72(5):737-740.

Watanabe, K. 1977. Successful ovary culture and production of $F$ hybrids and androgenic haploids in Japanese Chrysanthemum species. J. Hered. 68:317-320.

Wiens, D. 1984. Ovule survivorship, brood size, life history, breeding systems, and reproductive success in plants. Oecologia (Berlin) 64:4753 .

Wilkins, H.F. (cd.). 1979. Reference guide to commercial greenhouse crop production. Univ. of Minnesota, St. Paul.

Williams, P.H. and C.B. Hill. 1986. Rapid-cycling populations of Brassica. Science 232:1385-1389. 